\section{Glycemic Control and Awareness of Insulin} Therapy

Yegor Pashchenko, MS-4', Daniel H. Clausing, MS-41, Elizabeth Ablah, Ph.D., MPH ${ }^{1,2}$, Hayrettin Okut, Ph.D.,2,3, Georges C. Elhomsy, M.D., FACP, FACE ${ }^{1,4,5}$

${ }^{1}$ University of Kansas School of Medicine-Wichita, Wichita, KS

${ }^{2}$ Department of Population Health

${ }^{3}$ Office of Research

${ }^{4}$ Department of Internal Medicine

${ }^{5}$ Wichita Diabetes and Endocrinology, Wichita, KS

Received March 24, 2021; Accepted for publication June 7, 2021; Published online Oct. 14, 2021

\section{ABSTRACT}

Introduction. Glycemic control is associated with better health outcomes among patients with diabetes. No previous research has examined the relationship between knowledge of one's insulin dose and glycemic control. This study sought to determine if patients who accurately recalled their insulin dose achieved better glycemic control than patients who could not remember their dose.

Methods. Interviews were conducted with 106 patients. Data were collected during patients' appointments at two endocrinology clinics in Wichita, Kansas from May 29, 2018 to February 15, 2019. Adequate glycemic control was defined as an HbAlc of less than 7.5\%. A multiple logistic regression model was developed to identify factors associated with glycemic control.

Results. Of the 109 patients asked to participate, 105 agreed to participate in the study. About half $(45 \%, \mathrm{n}=48)$ were male. Patients' mean age was 50 years $(\mathrm{SD}=17)$. Seventy-seven percent $(\mathrm{n}=81)$ were overweight (body mass index (BMI) of 25 to 29.9) or obese (BMI $>30$ ). Patients who correctly stated their insulin dose had a mean Hemoglobin Alc (HbAlc) of 6.9\% (SD = 0.98), whereas those who incorrectly stated their dose had a mean HbAlc of 9.5\% ( $\mathrm{SD}=1.9$; $\mathrm{p}<0.0001$ ).

Conclusions. There was a significant relationship between knowledge of one's insulin dose and adequate glycemic control.

\section{Kans J Med 2021;14:249-252}

\section{INTRODUCTION}

Poor glycemic control is the leading cause of hospital admissions among patients with diabetes in the United States. ${ }^{1}$ Adequate outpatient management could decrease the morbidity of the disease substantially. Previous work by Rohlfing et al. ${ }^{2}$ established glycated hemoglobin (HbAlc) as an ideal marker of glycemic control among patients with diabetes. HbAlc became the gold-standard for glycemic monitoring because it has been correlated with adverse outcomes, especially microvascular complications. ${ }^{3}$ Although the relationship between adverse health complications and elevated HbAlc is well-documented, and treatment protocols to maintain a normal blood glucose level are similarly well known, patients struggle to maintain adequate glycemic control. $^{4}$

Although adequate glycemic control is elusive for many patients, improved glycemic control can occur when patients with diabetes receive information on the benefits of exercise, glucose monitoring, and a proper diet. ${ }^{5}$ Greater patient knowledge about diabetes management can lead to better health outcomes. ${ }^{6}$ Yet, no studies to date have

\section{KANSAS JOURNAL of MEDICINE}

documented whether knowledge of one's insulin dose was associated with one's glycemic control. The objective of this study was to determine if patients with insulin-dependent diabetes who could recall their insulin dose accurately achieve better glycemic control than patients who could not recall their dose.

\section{METHODS}

This study was approved by the University of Kansas Medical Center's Institutional Review Board.

Participants. Adults (18 years or older) with diagnosed insulindependent diabetes who agreed to participate in the study were interviewed at one of two endocrinology clinics in Wichita, Kansas. All participants were taking basal-bolus insulin for glucose control. The medical team consisted of one endocrinologist and two physician assistants. Patients were interviewed from May 29, 2018 through February 15,2019 . Patients who were non-verbal or missed their appointment were not eligible to participate in the study.

Instruments. A survey was administered via semi-structured, face-to-face interview. The 25-item interview tool included variables that can be associated with poor glycemic control, such as weekly time spent performing moderate physical activity, ${ }^{7}$ body mass index (BMI), ${ }^{8}$ depression diagnosis, ${ }^{9}$ frequency of blood glucose checks, ${ }^{10}$ and type of insurance." Basic demographic information also was requested, including age, sex, race, ethnicity, and educational status. In addition to the interview, patient health information was abstracted from medical records. Abstracted data included number of missed clinic appointments in the last 12 months, number of other medications currently prescribed, ${ }^{12}$ duration of insulin treatment, and their most recent $\mathrm{HbAlc}$ value.

Procedures. At the beginning of each appointment, eligible patients were asked if they were interested in participating. After obtaining consent, one researcher administered the interview. Each patient was interviewed in a private exam room. During the interview, the patient's responses were entered into a database. After the interview, the chart data were abstracted. The patient's prescribed insulin dose was abstracted from the chart and compared to the dose reported by the patient. If the self-reported and medical chart doses were the same, the patient was identified as having reported the insulin dose accurately.

Data Analysis. A sample size of 100 patients with diabetes (50 in each knowledge group) was determined to detect a difference of $40 \%$ between groups. Data were analyzed with SAS version 9.4 (2018, SAS Int. Inc., Cary, NC). Frequencies, proportions, means, and standard deviation were calculated. Likelihood ratio chi-square and Fisher's exact tests were used to test the significance of the association between two nominal or categorical variables. Prior to the main analyses, the Shapiro-Wilk test was conducted to test for normal distribution of outcomes. Hence, the rank transform approach to nonparametric methods was used as combination of PROC RANK and PROC GLM in SAS. Several longstanding nonparametric tests including KruskalWallis are either exactly equivalent to rank transform tests or are nearly 
KANSAS JOURNAL of MEDICINE INSULIN THERAPY AWARENESS

continued.

equivalent to them. Least-squares means (to estimate the marginal means over a balanced population) were used for pairwise comparisons of groups by Tukey test using Kramer adjustment. Mann-Whitney $\mathrm{U}$ test and t-test methods were used to test the differences between means of two independent groups. Univariate linear regression models were used to test the association among HbAlc, number of minutes of moderate exercise each week and BMI. All statistical tests at $\mathrm{p} \leq 0.05$ were considered significant.

\section{RESULTS}

Of the 109 patients who met inclusion criteria, 105 patients agreed to participate in the study (96\%). The mean patient age was 50 years $(\mathrm{SD}=17$; Table 1). Most of the sample $(80 \%, \mathrm{n}=84)$ reported they were Caucasian, and $53 \%$ percent of patients $(\mathrm{n}=56)$ were female. Sixty-two percent of patients $(\mathrm{n}=65)$ reported having completed high school or some college. Fifty-seven percent $(n=60)$ of patients reported being employed. Approximately three-quarters of patients $(78 \%, \mathrm{n}$ $=82$ ) were overweight (BMI 25 - 29.9) or obese (BMI >30). Forty-five percent of patients $(n=48)$ had inadequate glycemic control $(\geq 7.5 \%)$, with a mean $\mathrm{HbAlc}$ of $9.5 \%(\mathrm{SD}=1.9)$. More than half of patients $(55 \%$, $\mathrm{n}=58$ ) had adequate glycemic control, with a mean HbAlc of $6.6 \%$ $(\mathrm{SD}=0.98)$.

Bivariate analysis suggested that patients who correctly stated their insulin dose had a mean $\mathrm{HbAlc}$ of $6.9 \%$ ( $\mathrm{SD}=0.98$ ), whereas those who incorrectly stated their insulin dose had a mean $\mathrm{HbAlc}$ of $9.5 \%$ (SD = $1.9, \mathrm{p}<0.0001$ ). A regression analysis was conducted to determine the association between the insulin dose error (the number of insulin units greater than or less than reported by the patient) and their resultant HbAlc. For every 29.5 units of insulin less than the patient's prescribed dose, the resultant HbAlc increased by one point. There also was a positive correlation between minutes of moderate physical activity per week and HbAlc $(\mathrm{p}=0.02)$.

Although a greater insulin dose error and more minutes of exercise were the only variables associated with elevated $\mathrm{HbAlc}$ in bivariate analyses, a multivariate model suggested that other factors also contribute to an elevated $\mathrm{HbAlc}$. Specifically, major depressive disorder ( $p=0.03)$, elevated BMI $(p=0.04)$, type of insurance $(p<0.0001)$, increased duration of insulin use $(p=0.01)$, a greater number of missed clinic appointments ( $p<0.0001)$, fewer glucose checks $(p=0.026)$, and a greater number of prescribed medications $(\mathrm{p}=0.02)$ also were associated significantly with elevated $\mathrm{HbAlc}(\mathrm{F}(19,72)=7.57, \mathrm{p}<0.0001, \mathrm{R} 2$ 0.666). Patients who correctly stated their insulin dose, on average, had a $2.6 \%$ lower HbAlc value than patients who incorrectly stated their insulin dose, when accounting for these other variables in the model. Additionally, for every 100 minutes of moderate physical activity, patients were likely to have a $0.2 \%$ increase in $\operatorname{HbAlc}(\mathrm{p}=0.02)$.
Table 1. Patient characteristics.

\begin{tabular}{|l|c|}
\hline Patient characteristics* & $\mathbf{n}(\%)$ \\
\hline Age & \\
\hline $18-25$ & $8(8)$ \\
\hline $26-35$ & $23(22)$ \\
\hline $36-45$ & $13(12)$ \\
\hline $46-55$ & $13(12)$ \\
\hline $56-65$ & $23(22)$ \\
\hline $66-75$ & $20(19)$ \\
\hline 76 or older & $6(6)$ \\
\hline Education level & \\
\hline High school or less & $33(31)$ \\
\hline Some college & $32(30)$ \\
\hline College degree & $29(28)$ \\
\hline Graduate degree & $10(9)$ \\
\hline Race and ethnicity & \\
\hline Caucasian & $89(84)$ \\
\hline African American & $9(6)$ \\
\hline Hispanic & $4(4)$ \\
\hline Asian American & $5(4)$ \\
\hline Other or more than one race/ethnicity & $3(3)$ \\
\hline Employment status & \\
\hline Employed & $53(50)$ \\
\hline Retired & $28(27)$ \\
\hline Disabled & $11(10)$ \\
\hline Unemployed & $13(12)$ \\
\hline Student & $23(4)$ \\
\hline Body Mass Index & $27(23)$ \\
\hline Normal weight & $55(60)$ \\
\hline Overweight & \\
\hline Obese & \\
\hline Glycemic control & $(55)$ \\
\hline Adequate glycemic control (HbAlc less than $7.5 \%)$ \\
\hline $\begin{array}{l}\text { Inadequate glycemic control (HbAlc greater than or } \\
\text { equal to 7.5\%) }\end{array}$ \\
\hline
\end{tabular}

*Some categories do not add up to the total number of participants because some patients left a survey question blank or selected multiple options (e.g., they were retired and disabled or Hispanic and African American).

\section{DISCUSSION}

The purpose of this study was to determine if there was an association between knowledge of one's insulin dose and glycemic control. The current study suggested that patients who accurately reported their insulin dose had a lower mean HbAlc than those who inaccurately reported their insulin dose. These findings are consistent with other studies that have examined the association between glycemic control and diabetes knowledge, such as proper diet, ${ }^{5}$ diabetes medication awareness, ${ }^{6}$ and symptom recognition of hypoglycemia. ${ }^{13}$ This might suggest that increasing patient involvement in diabetes management can lead to better glycemic control. It was also possible that this association is a biproduct of healthier patients being more involved in their healthcare. 
In the current study, patients who inaccurately reported their insulin dose were more likely to have a higher HbAlc. For every 30 units that patients under-reported their insulin dose, their HbAlc increased by one percentage point. This suggested that the magnitude of a patient's insulin dose error correlated to the amount that their HbAlc was elevated.

In addition to insulin dose error, the current study also suggested that other factors are associated with poor glycemic control: longer duration of insulin use, fewer daily blood glucose checks, ${ }^{14}$ certain comorbid medical factors, and social factors. Another factor that varies between individuals with diabetes is the number of times they check their blood sugar every day. This study suggested that patients who check their glucose more often had lower HbAlc values. This was consistent with previous literature. ${ }^{14}$

In addition to diabetes management factors, other medical comorbidities, such as depression and high BMI, also were associated with increased HbAlc values. A study by Lustman et al. ${ }^{15}$ suggested that untreated depression was associated with poor diabetes medication adherence. The current study suggested there was not an association between poor glycemic control and having a diagnosis of depression. One potential reason for this discrepancy was that all participants in the current study who reported a diagnosis of depression were being treated for their depression; however due to the limited scope of the survey, the extent, severity, and medication responsiveness of their depression was not taken into account during data analysis. Moreover, Brieler et al. ${ }^{16}$ suggested that the use of antidepressants can improve glycemic control among depressed patients with diabetes. This might suggest that recognizing, diagnosing, and treating depression can lead to better glycemic control. Another interpretation might be that patients with good glycemic control are less likely to feel depressed.

The current study suggested that BMI was associated with glycemic control. This was inconsistent with a study by Koga et al. ${ }^{17}$ that suggested no correlation with BMI. A 2001 study by Boulé et al. ${ }^{8}$ suggested that greater physical activity lead to lower HbAlc levels, whereas the current study suggested an association between more time spent exercising and worse HbAlc values, which was also inconsistent with the findings of Boulé et al. ${ }^{8}$ It is unclear why more exercise would be associated with poorer glycemic control. One explanation is that some of the participants in the present study were farmers or other outside laborers who had high levels of physical activity, but who also experienced barriers to accessing their insulin during the workday. Another explanation was that an unmeasured factor was associated with both increased activity and poorer glycemic control (e.g., type of exercise), and this factor was not assessed by the survey. Regardless of the reason for this odd relationship, medical comorbidities like depression status and BMI are important factors to explore in predicting glycemic control.

In addition to considering the role of medical comorbidities when determining the factors that affect glycemic control, the role of concomitant social factors also was important. One such social factor in the current study was missed clinic appointments. The study suggested that patients who miss six or more clinic appointments had higher HbAlc values than patients who missed one or fewer clinic appointments. This supported previous research by Karter et al., ${ }^{18}$ indicating that patients who missed more than $30 \%$ of their appointments had higher HbAlc
KANSAS JOURNAL of MEDICINE INSULINTHERAPY AWARENESS

continued.

values, with a mean $\mathrm{HbAlc}$ of $8.6 \%$. Another social factor explored in the current study was the association between being a patient on Medicaid and glycemic control. The current study suggested no association, which was inconsistent with a study by Healy et al. ${ }^{11}$ where being a Medicaid patient was associated with poor diabetes medication adherence. The lack of association between Medicaid status and poor glycemic control in the current study could be attributed to the small sample size and lack of variability in participants' insurance type.

Limitations. The current study had several potential limitations. As a cross-sectional study, a causal relationship between glycemic control and other factors could not be established. Due to time constraints, only five to ten minutes were dedicated to interviewing each patient; this limited the number of potential factors that could be surveyed regarding glycemic control. For example, it could have been useful to include data about patients' attitudes toward healthcare, literacy, ${ }^{19}$ medical knowledge, ${ }^{20}$ living situation, ${ }^{21}$ relationship status, number of children, diet characteristics, ${ }^{9}$ completing a depression screening, and access to transportation. ${ }^{22}$ Additionally, the interview only included patients during an eight-month period; this may have resulted in a less representative sample due to seasonal variation. The studies smaller sample size created some oddities in generating a model. For example, individual categories within variables, such as five missed clinic appointments vs. four, were not necessarily correlated with different HbAlc values, but they were considered significant and included in the model if there were at least two distinct groups (e.g., six missed clinic appointments were associated with higher HbAlc than zero missed clinic appointments). Finally, the interview questions could be subject to recall bias and self-reporting bias which should be considered when interpreting the results of this study.

\section{CONCLUSIONS}

This study suggested that patients who have adequate knowledge of insulin dose have better glycemic control, when controlling for insulin dose, minutes of exercise, depression status, BMI, and type of insurance. Additionally, patients who reported higher levels of moderate physical activity had higher HbAlc values.

\section{REFERENCES}

${ }^{1}$ Centers for Disease Control and Prevention. National Diabetes Statistics Report, 2017. Atlanta, GA: Centers for Disease Control and Prevention, U.S. Dept of Health and Human Services; 2017.

${ }^{2}$ Rohlfing CL, Wiedmeyer HM, Little RR, England JD, Tennill A, Goldstein DE. Defining the relationship between plasma glucose and HbAlc: Analysis of glucose profiles and HbAlc in the Diabetes Control and Complications Trial. Diabetes Care 2002; 25(2):275-278. PMID: 11815495.

${ }^{3}$ Ohkubo Y, Kishikawa H, Araki E, et al. Intensive insulin therapy prevents the progression of diabetic microvascular complications in Japanese patients with non-insulin-dependent diabetes mellitus: A randomized prospective 6-year study. Diabetes Res Clin Pract 1995; 28(2):103-117. PMID: 7587918.

4 Akbar DH, Al-Gamdi AA. Common causes of admission in diabetics. Saudi Med J 2000;21(6):539-542. PMID: 11500701.

5 Duncan I, Ahmed T, Li Q, et al. Assessing the value of the diabetes educator. Diabetes Educ 2011; 37(5):638-657. PMID: 21878591.

6 Al-Qazaz HK, Sulaiman SA, Hassali MA, et al. Diabetes knowledge, medication adherence and glycemic control among patients with type 2 diabetes. Int J Clin Pharm 2011; 33(6):1028-1035. PMID: 22083724. 


\section{KANSAS JOURNAL of MEDICINE}

\section{INSULIN THERAPY AWARENESS}

\section{continued.}

${ }^{7}$ Umpierre D, Ribeiro PA, Kramer CK, et al. Physical activity advice only or structured exercise training and association with HbAlc levels in type 2 diabetes: A systematic review and meta-analysis. JAMA 2011;305(17):17901799. PMID: 21540423.

${ }^{8}$ Boulé NG, Haddad E, Kenny GP, Wells GA, Sigal RJ. Effects of exercise on glycemic control and body mass in type 2 diabetes mellitus: A meta-analysis of controlled clinical trials. JAMA 2001; 286(10):1218-1227. PMID: 11559268

9 Katon W, Russo J, Lin EH, et al. Diabetes and poor disease control: Is comorbid depression associated with poor medication adherence or lack of treatment intensification? Psychosom Med 2009; 71(9):965-972. PMID: 19834047.

10 Buckingham B, Caswell K, Wilson DM. Real-time continuous glucose monitoring. Curr Opin Endocrinol Diabetes Obes 2007; 14(4):288-295. PMID: 17940454.

${ }^{11}$ Healy SJ, Black D, Harris C, Lorenz A, Dungan KM. Inpatient diabetes education is associated with less frequent hospital readmission among patients with poor glycemic control. Diabetes Care 2013; 36(10):29602967. PMID: 23835695.

${ }^{12}$ Balkrishnan, R. Predictors of medication adherence in the elderly. Clin Ther 1998; 20(4):764-771. PMID: 9737835.

13 Angamo MT, Melese BH, Ayen WY. Determinants of glycemic control among insulin treated diabetic patients in Southwest Ethiopia: Hospital based cross sectional study. PLoS One 2013; 8(4):e61759. PMID: 23620789. ${ }^{14}$ Miller KM, Beck RW, Bergenstal RM, et al. Evidence of a strong association between frequency of self-monitoring of blood glucose and hemoglobin Alc levels in TID exchange clinic registry participants. Diabetes Care 2013; 36(7):2009-2014. PMID: 23378621.

${ }^{15}$ Lustman PJ, Clouse RE. Depression in diabetic patients: The relationship between mood and glycemic control. J Diabetes Complications 2005; 19(2):113-122. PMID: 15745842.

16 Brieler JA, Lustman PJ, Scherrer JF, Salas J, Schneider FD. Antidepressant medication use and glycaemic control in co-morbid type 2 diabetes and depression. Fam Pract 2016; 33(1):30-36. PMID: 26743722.

17 Koga M, Matsumoto S, Saito H, Kasayama S. Body mass index negatively influences glycated albumin, but not glycated hemoglobin, in diabetic patients. Endocr J 2006; 53(3):387-391. PMID: 16717395.

${ }_{18}$ Karter AJ, Parker MM, Moffet HH, et al. Missed appointments and poor glycemic control: An opportunity to identify high-risk diabetic patients. Med Care 2004; 42(2):110-115. PMID: 14734947.

19 Rothman R, Malone R, Bryant B, Horlen C, DeWalt D, Pignone M. The relationship between literacy and glycemic control in a diabetes diseasemanagement program. Diabetes Educ 2004; 30(2):263-273. PMID: 15095516.

${ }^{20}$ Bains SS, Egede LE. Associations between health literacy, diabetes knowledge, self-care behaviors, and glycemic control in a low income population with type 2 diabetes. Diabetes Technol Ther 2011; 13(3):335-341. PMID: 21299402.

${ }^{21}$ Forsander GA, Sundelin J, Persson B. Influence of the initial management regimen and family social situation on glycemic control and medical care in children with type I diabetes mellitus. Acta Paediatr 2000; 89(12):14621468. PMID: 11195237.

${ }^{22}$ Syed ST, Gerber BS, Sharp LK. Traveling towards disease: Transportation barriers to health care access. J Community Health 2013; 38(5):976-993. PMID: 23543372.

Keywords: glycemic control, medication adherence, hemoglobin Alc, patient education, health knowledge 